\title{
INNOVATIONS FOR STRUCTURAL SYSTEM EDUCATION IN ARCHITECTURE
}

\author{
Saniye Karaman Öztaş ${ }^{1}$, Cahide Aydin İpekçi²
}

\begin{abstract}
Structural systems, which play an important role in today's architectural education, have become an issue that is analyzed by mega structures using different disciplines in the process from the design stage to the construction stage. While design and structural system studies are performed together in practice, architecture students usually have difficulty in reflecting their learning from the structural system course into their design studio in architectural education. In this study, information about education method for "Structural System and Technologies I" course, carried out in the fourth semester (second class) in Department of Architecture in Gebze Technical University, was primarily given. Unlike previous teaching methods in this course scope, a structural system modeling to solve the given design problem was requested from the students during spring semester 2015. It was aimed to provide the students with an understanding of general design principles involving structural elements and learning about the necessity in which the structural system should be considered in conjunction with the architectural design, concluding with a two-week assignment. A survey was conducted among 55 architecture students in order to evaluate the outcomes of the assignment. According to the survey results, $61 \%$ of the students stated that function, form, and structural system affect one another. $20 \%$ of them stated that function, form, and structural system, respectively, have an order of importance in the design process. $9 \%$ of them stated that structural system determine form and function. $6 \%$ of them stated that form, function, and structural system, respectively, have an order of importance in the design process. Finally, $4 \%$ of them stated that their relations change depending on the condition. Innovative teaching method in this study is found to be successful because the students have experienced the importance of materials in structural system and learned how to integrate structural system course to architectural design studio. It is intended that this study will benefit architecture students and educators.
\end{abstract}

UDC Classification: 378, 72, 624.01, DOI: http://dx.doi.org/10.12955/cbup.v3.610

Keywords: Education, architecture, innovation, structural system

\section{Introduction}

"It is clear that our built environment has not got the qualities that we think it should have. Education is an excellent way of improving our expectations for changes in the right direction" (Thornberg, 2005).

Architectural education consists of numerous science and humanities disciplines. However, architectural education has the ability to assemble contradictory and differentiated particles of the world in our design environment with clear and holistic solutions in creative ways (İnceday1, 2010). Architectural education for the future should be capable of adapting to a changing world by teaching students the ways to access the necessary information and providing them with solutions to the problems (Erpi, 1995). To understand structural system fiction, the behaviors of the structural systems, the importance of working with structural system engineers for the structural system design, and how to develop knowledge and skills acquired during architectural education are the requirements of structural systems course in architecture (İpekçi \& Coşgun, 2011). Architects need a basic qualitative understanding of structural theory in order to design rational buildings, only then, will a structure be born healthy, vital, and possibly beautiful (Salvadori, 1975).

Reflecting learning from the structural systems course into the architectural design studio is important for architectural education. However, architecture students have difficulty in integrating structure into their design studio. The teaching of a structures course within academic architecture programs faces a fundamental problem in the teaching methods because the architecture students struggle with a traditional engineering-based approach to structural instruction, which is increasingly unsuitable (Hyett, 2000; Aziz, Fahmi, \& Bane, 2010). According to Vassigh, the integration problem is due to the

\footnotetext{
1 Saniye Karaman Öztaş, Department of Architecture, Faculty of Architecture, Gebze Technical University, Turkey, saniyekaraman@gtu.edu.tr

2 Cahide Aydin İpekçi, Department of Architecture Faculty of Architecture, Gebze Technical University, Turkey, caipekci@gtu.edu.tr
} 
structures curriculum, the teaching methods, and the instructional tools, which are borrowed from engineering courses; they do not satisfy the architecture students' need (Vassigh, 2005; Aziz et al., 2010). Education period for undergraduate program in the Department of Architecture in Gebze Technical University is four years and ongoing since 2008. "Structural Systems and Technologies (III- III)" courses start in the fourth semester (second class) in this program and are carried out in three semesters (IV, V, and VI). "Structural Systems and Technologies I" course is aimed to teach behavior principles of force-loaded structure and structural system's development and applications. This course is theoretical and takes two hours per week. Structural system models about the buildings belonging to leading architects have been requested as a final assignment since 2009. It is aimed to provide an understanding of the structural systems, construction, and manufacturing techniques by constructing these models.

In this study, an innovative teaching method is used in the scope of "Structural Systems and Technologies I" course during spring semester 2015 in the Department of Architecture in Gebze Technical University. A structural system modeling, to solve the given design problem, is requested by the students. It is aimed to provide the students with an understanding of general design principles of the structural elements and learning about the necessity in which the structural system should be considered in conjunction with the architectural design, ending with a two-week assignment. A survey was conducted among 55 architecture students in order to evaluate the outcome of the assignment.

\section{A New Teaching Method for Structural System Education: Construction System Modeling}

An assignment titled "Modeling a structural system-Hanging object" was given to students in order to emphasize the necessity in which the structural system should be considered in conjunction with the architectural design. Two weeks were given to 55 students who were divided into 10 groups. A structural system model with a hanging object (free form with a 150-200 grams weight) in the air without any direct support from the bottom was requested. The assignment includes:

- A structural system model (scale: 1/1): the choice of material is optional (wood, paper, rope, wire, etc.). Design and structural systems should be considered together.

- Final report: describe the development process of the model and difficulties in assembling the parts of the model.

- Poster (A3): includes plans, sections, and elevations (scale: 1/5) of the model, images of the process. No details on how their structural system model should be designed were given in order not to interfere with the students' creativity.

\section{Construction System Modeling: Hanging Objects}

In this section, structural system models designed by ten groups are described. Structural system model of the first group was inspired by the bird's nest built in trees. System was designed as a tree cavity for the bird's nest as a result of various efforts. Wooden sticks and rope, as structural elements, and cardboard were used for the model. Some materials such as roasted chickpea were placed into the object to provide 150-200 grams weight (Figure 1).

Structural system model of the second group were inspired by "fractal" patterns. Fractal is a mathematical set consisting of a repeating pattern that displays at every scale. Cubes of different sizes, e.g. $10 \times 10 \times 10 \mathrm{~cm}, 7 \times 7 \times 7 \mathrm{~cm}, 5 \times 5 \times 5 \mathrm{~cm}$, and $3 \times 3 \times 3 \mathrm{~cm}$, were used. Objects were fastened with wire from three different nodes. Galvanized wire was used because of its strength and weight. Design integrity was provided using the same materials for the hanging object and structural elements (Figure 2). 


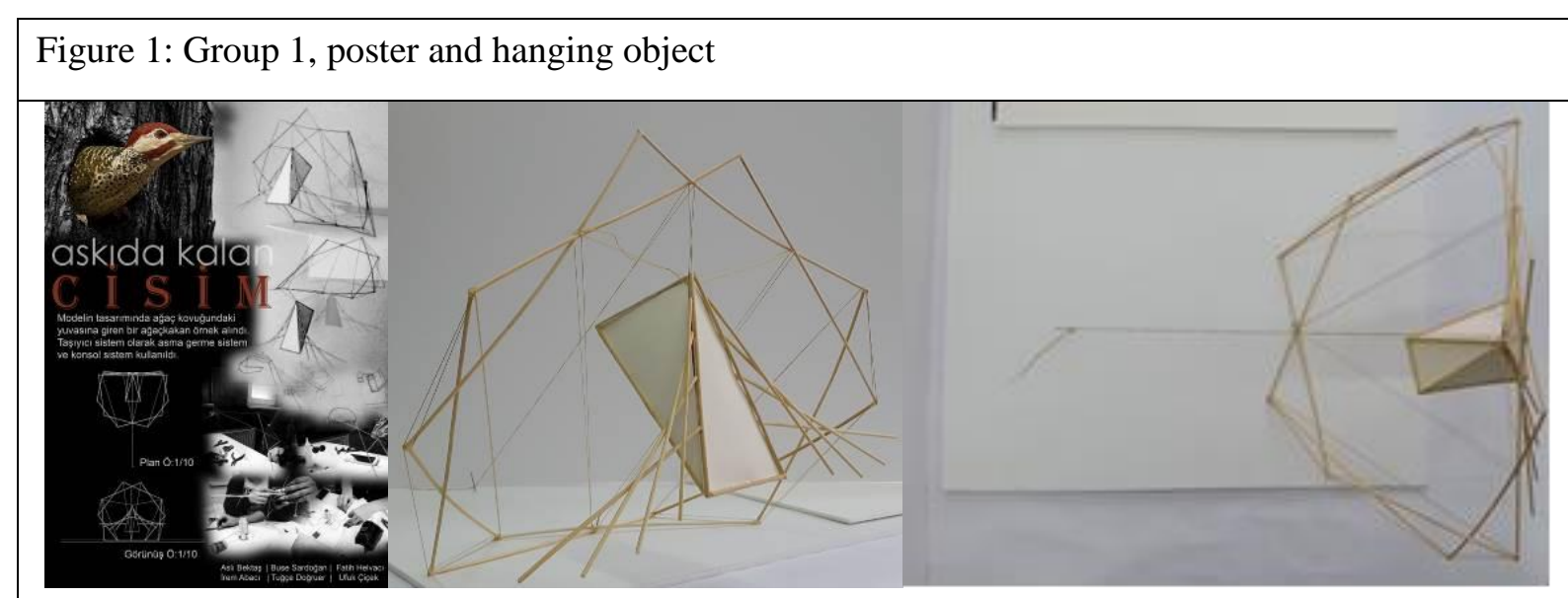

Source: Authors

Figure 2: Group 2, poster, development process of the model and hanging object
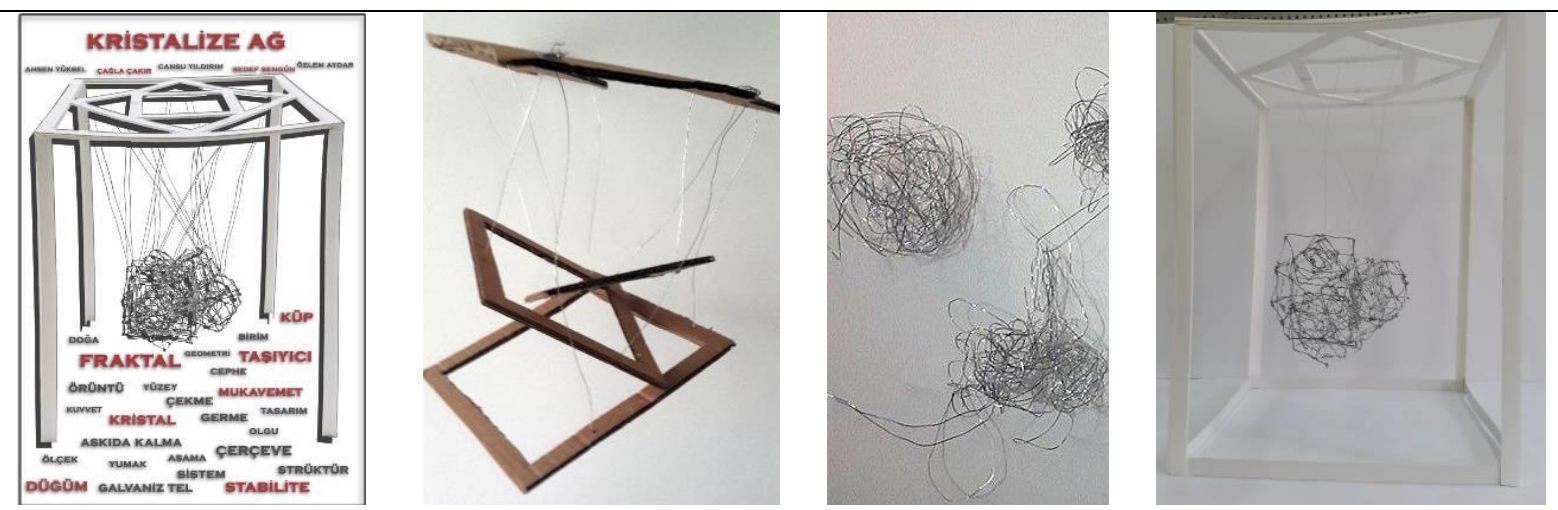

Source: Authors

The first efforts for structural system model of the third group using clay and sugar was not successful. Their final model consists of an object on frame-based structure and $5 \times 5 \mathrm{~mm}$ sizes of wooden sticks (Figure 3).

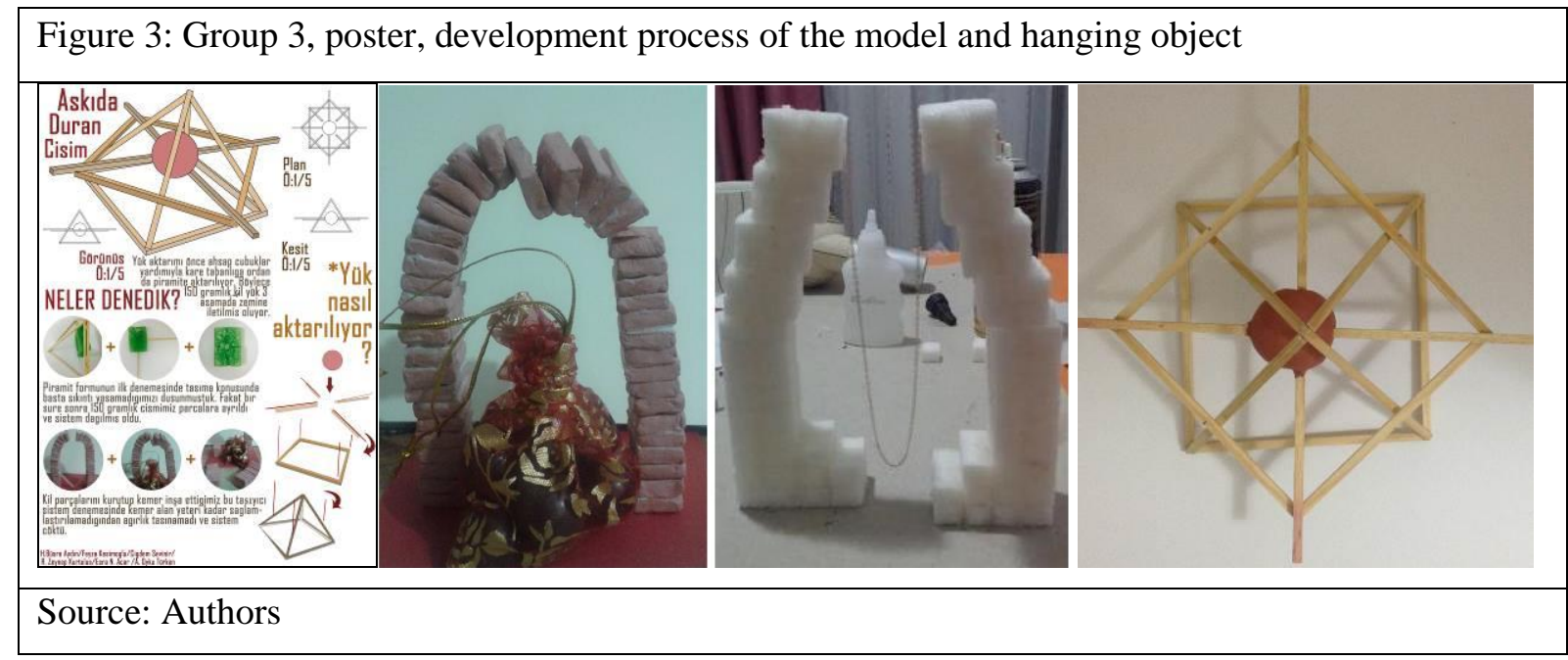

Structural system model of the fourth group were designed over abstract concepts. Initially, wood and gypsum had been used for the model. Because of fragmentation of gypsum, balsa ( $5 \times 5 \mathrm{~mm}$ ) (due to light weight), silicon (due to transparency and aesthetic appearance), gut (instead of steel wire ropes) were used. Balsa and silicon were used together by considering the harmony of the materials and 
strength of the structural elements and model. The object was influenced by expressionist movement and designed to represent the moment during an explosion. Silicon was shaped in cold water to reflect this effect (Figure 4).

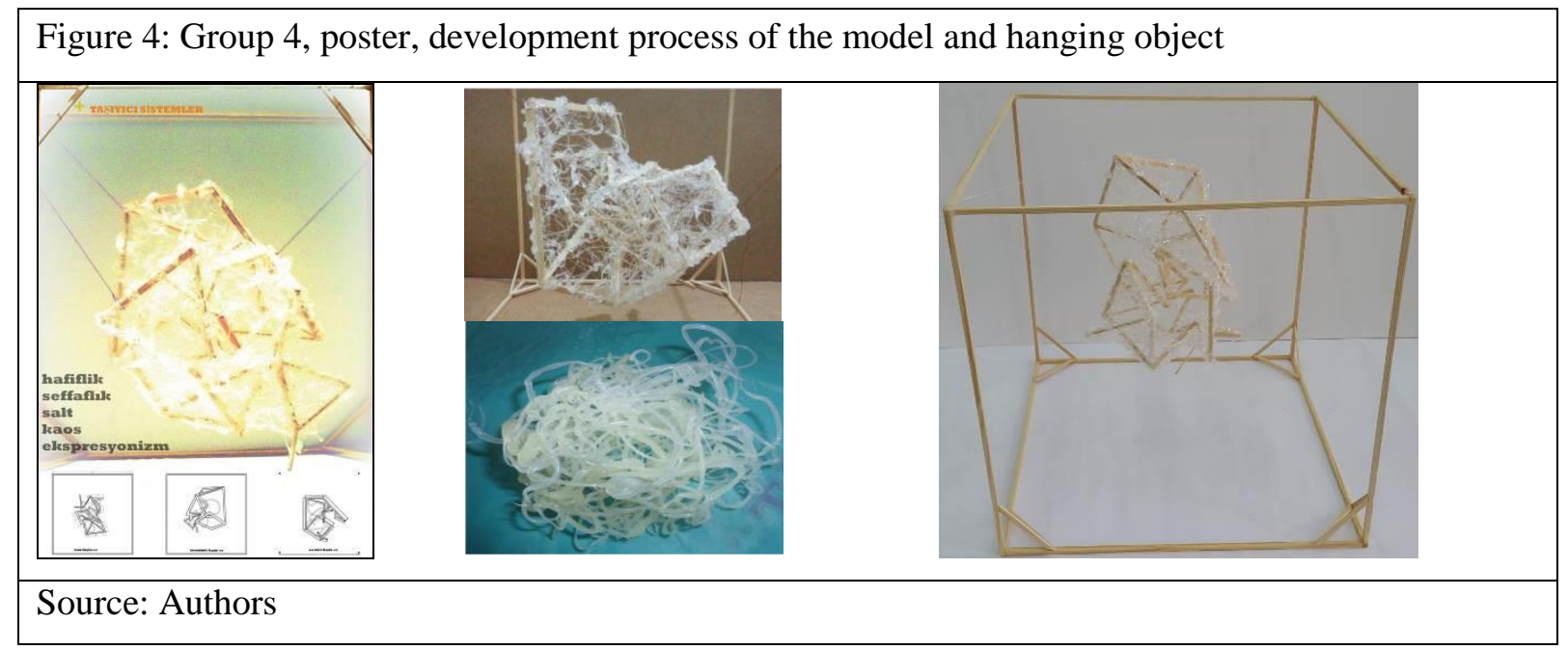

Structural system model of the fifth group were inspired by the hanging toys in children's crib. 12 screw nuts, providing desired weight of the object, and gut, as a structural element, were used. The form of the model was designed to be changeable with moving screws by gut (Figure 5).

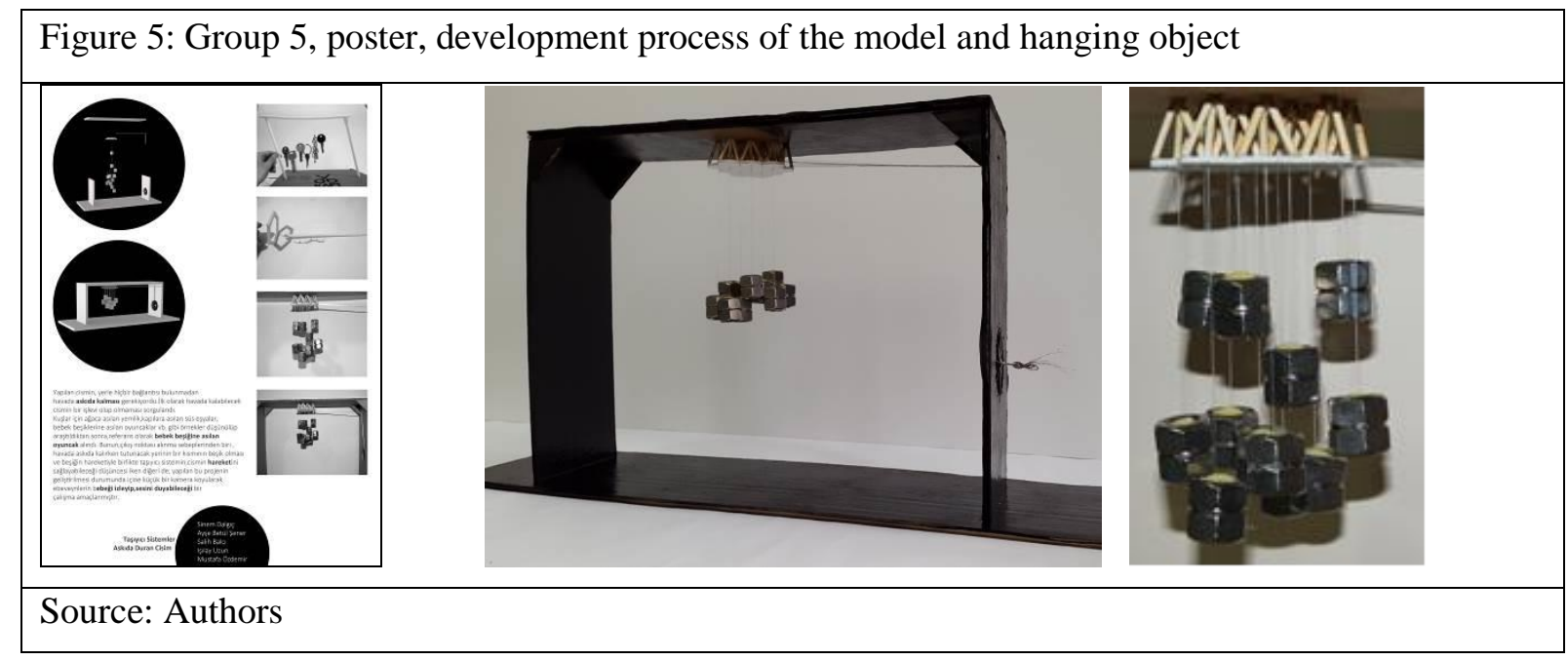

The sixth group designed a hanging object, which is similar to an atom with a nucleus within a sphere. Gut (because of the flexible and transparent properties), large and small pebbles (because of the weights and appearance), and rigid and lightweight plastic pulley were used (Figure 6).

The seventh group designed a moving system after drawing sketches. Gut (because of load carrying ability), cardboard, easily processed wooden sticks, metal screw nuts (as the object), plastic beads, and spray paint were used. The platforms (associated with the rail system) and the hanging objects (attached to the platform) acted in horizontal and vertical manner when guts were moved (Figure 7).

The eighth group first thought about designing a hanging object with magnets utilizing the push-pull feature of the magnetic force. However, it would be a difficult problem for 150-200 grams weight because of the constantly changing magnetic domain. Secondly, rectangular prism-shaped object divided into seven equal parts were designed and hung by gut. Guts were placed in different holes in a particular order. Fluctuation sensation was provided at a certain rhythm in the horizontal and vertical movement (Figure 8). 


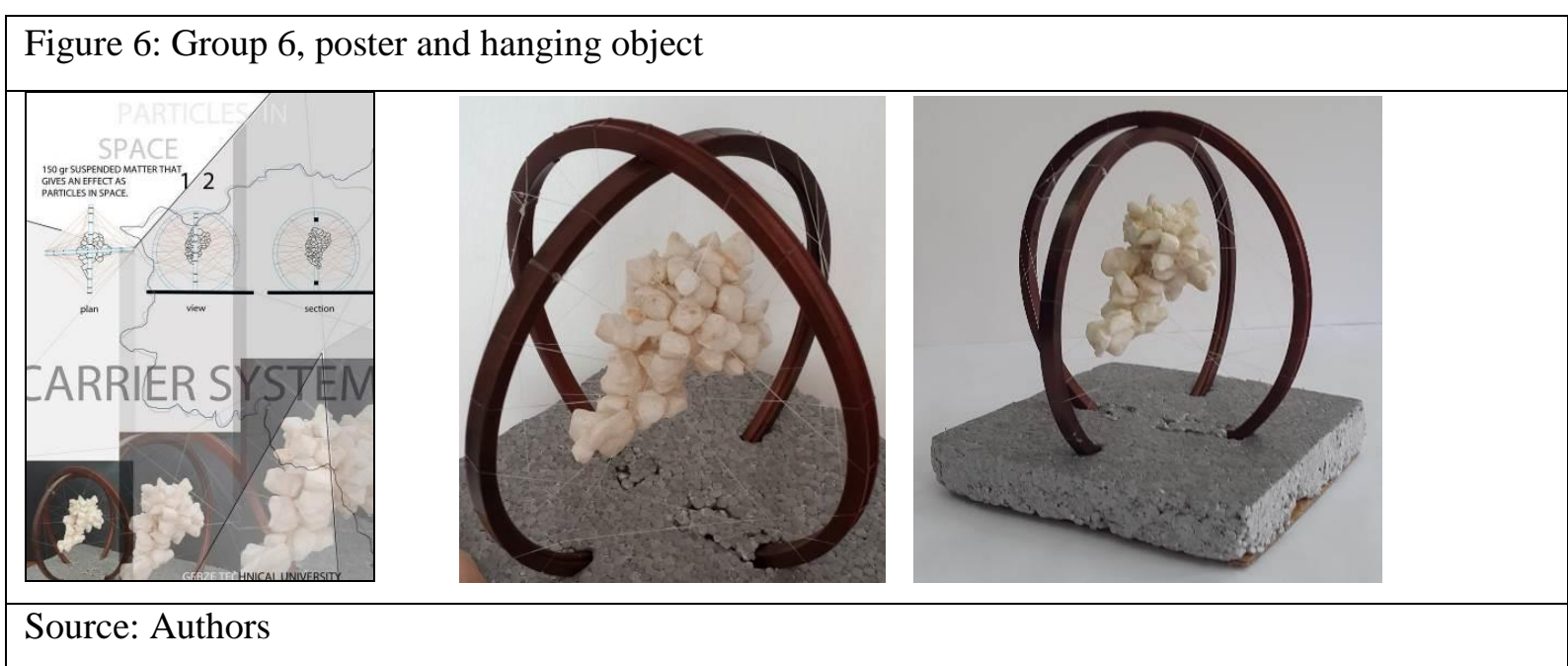

Figure 7: Group 7, poster, development process of the model and hanging object
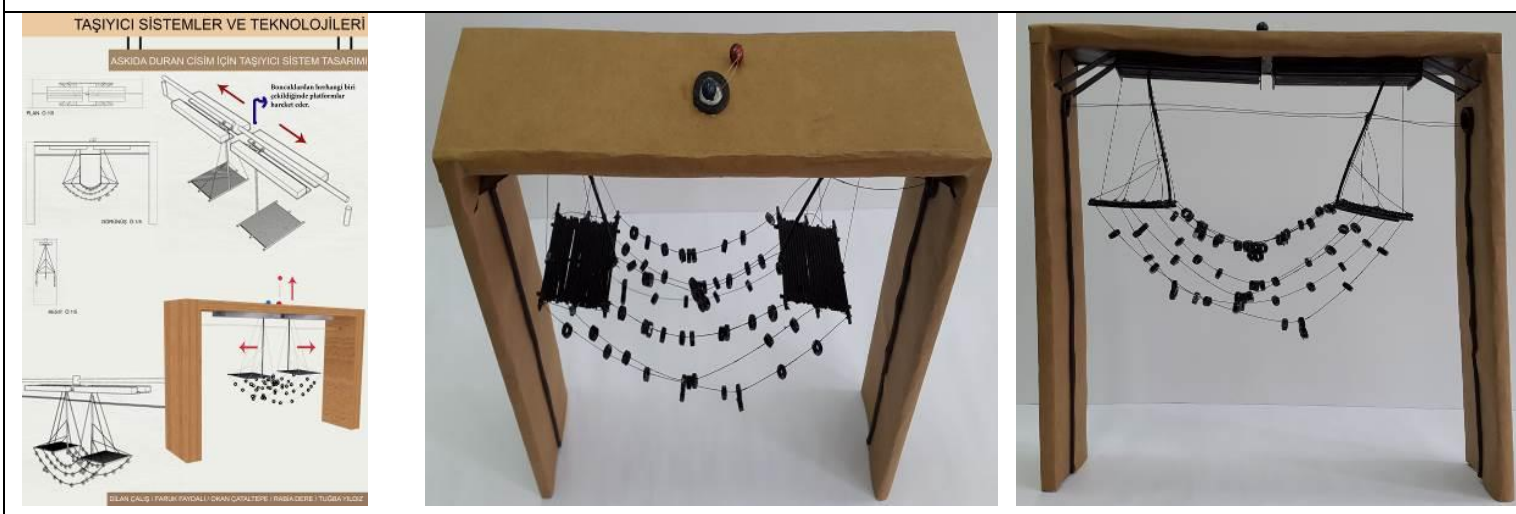

Source: Authors

Figure 8: Group 8, poster, development process of the model and hanging object
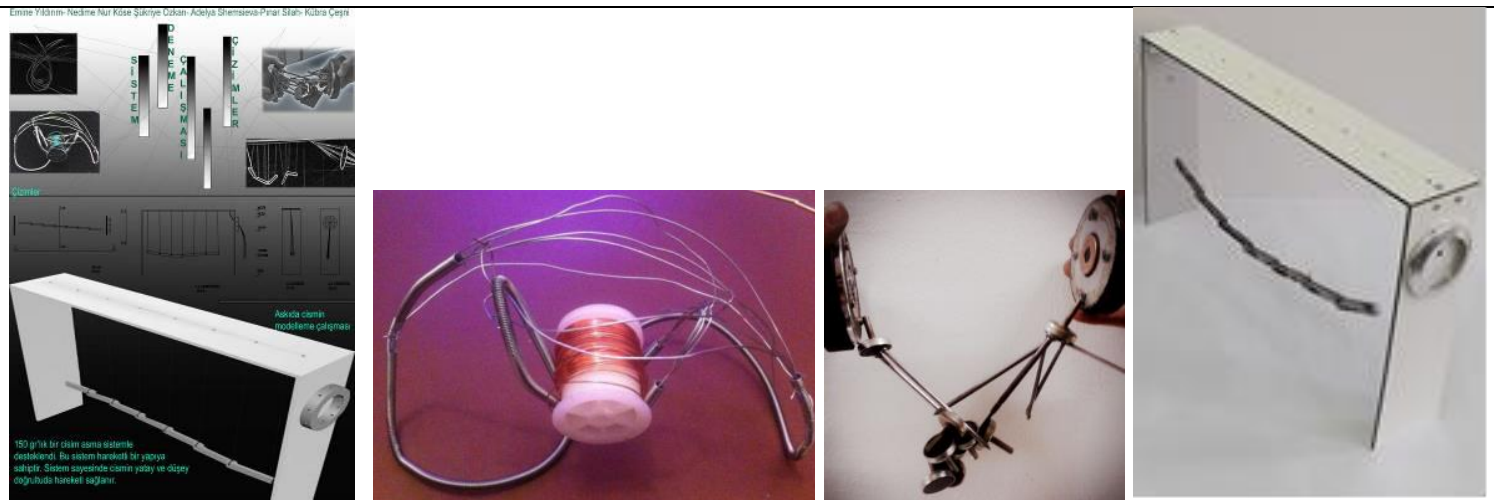

Source: Authors

Structural system model of the ninth group was designed based on three major structural elements, and the object was connected by wire to these elements. Firstly, pipettes were used as vertical structural elements, but it was decided that the material was not suitable. Wooden strips $(5 \times 5 \mathrm{~mm}, 40 \mathrm{~cm}$ in length), wire, foam, cardboard, nails, and screws, in maintaining the weight, were used (Figure 9).

The tenth group designed a structural system consisting of rings. Five metal rings, wire, and rope were used. Two rings were designed as hanging objects, while three of them, combined as an equilateral triangle, were designed as structural elements. A form was designed with two rings combined with ropes as hanging objects (Figure 10). 


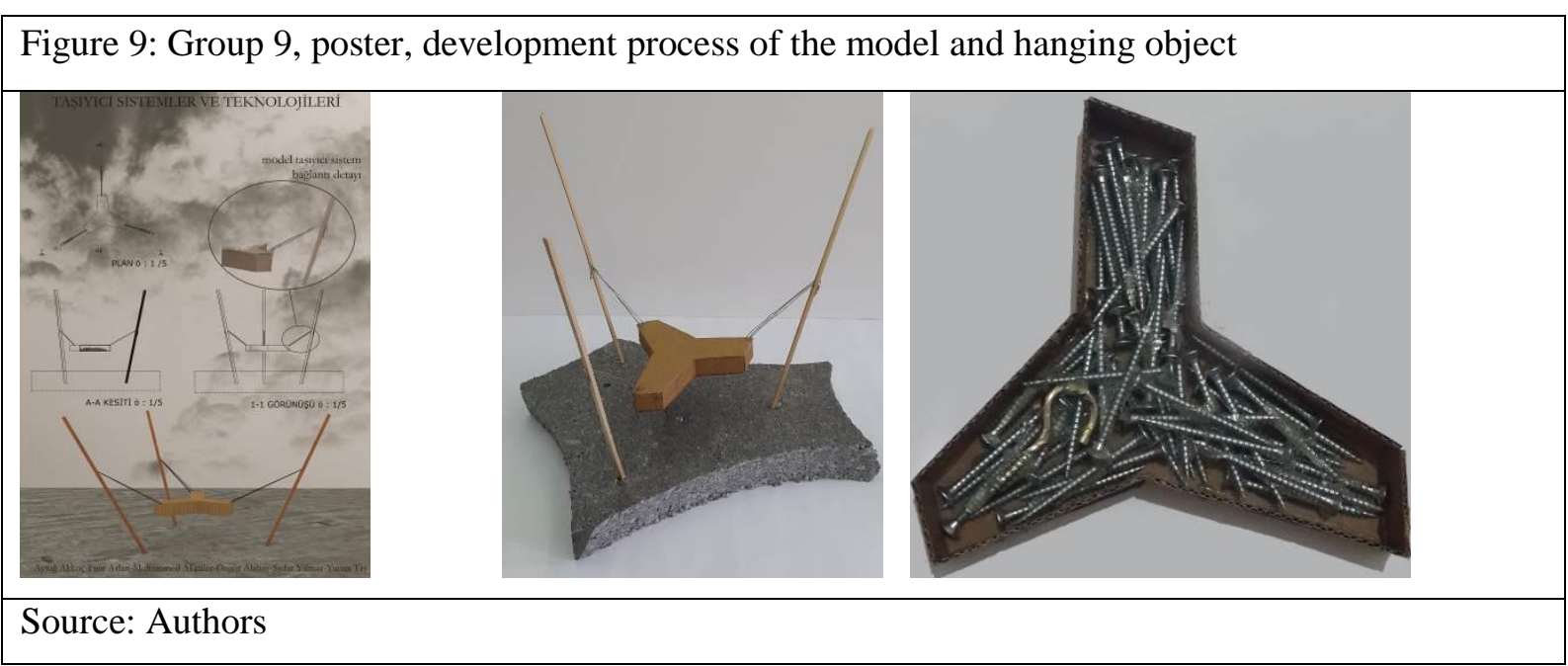

Figure 10: Group 10, development process of the model and hanging object
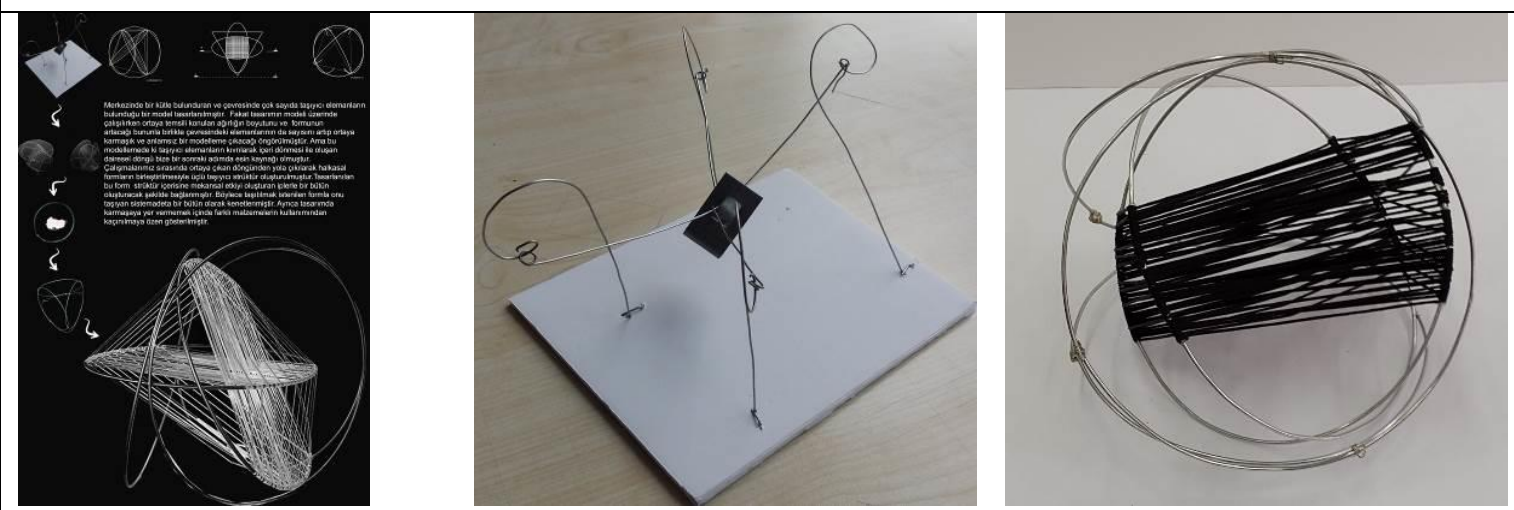

Source: Authors

\section{Evaluation of Construction System Modeling}

The study was evaluated with surveys of 55 students as a result of the structural system modeling. In the first part of the survey, Yes/No questions were included.

The first question in this part was about the form, function, and structural system relations for the architectural design process. $61 \%$ of the students stated that function, form, and structural system affect one another. $20 \%$ of them stated that function, form, and structural system, respectively, have an order of importance in the design process. $9 \%$ of them stated that structural system determine form and function. $6 \%$ of them stated that form, function, and structural system, respectively, have an order of importance in the design process. Finally, $4 \%$ of them stated that their relations change depending on the condition (Figure 11).

Figure 12 shows the suitability of the model according to the study scope, the number of students contributed to the study, time for the study, the dimensions of the model, structural system, form and material relations. The questions were answered by Yes or No.

The second part of the survey consisted of five questions including students' comments. Design process of their models, selected materials, the form of the resulting model, structural elements of the model, and their learning about this study were questioned. Most of the students stated that they had learned that the design and structural system should be considered together and that material is important for structural system. 


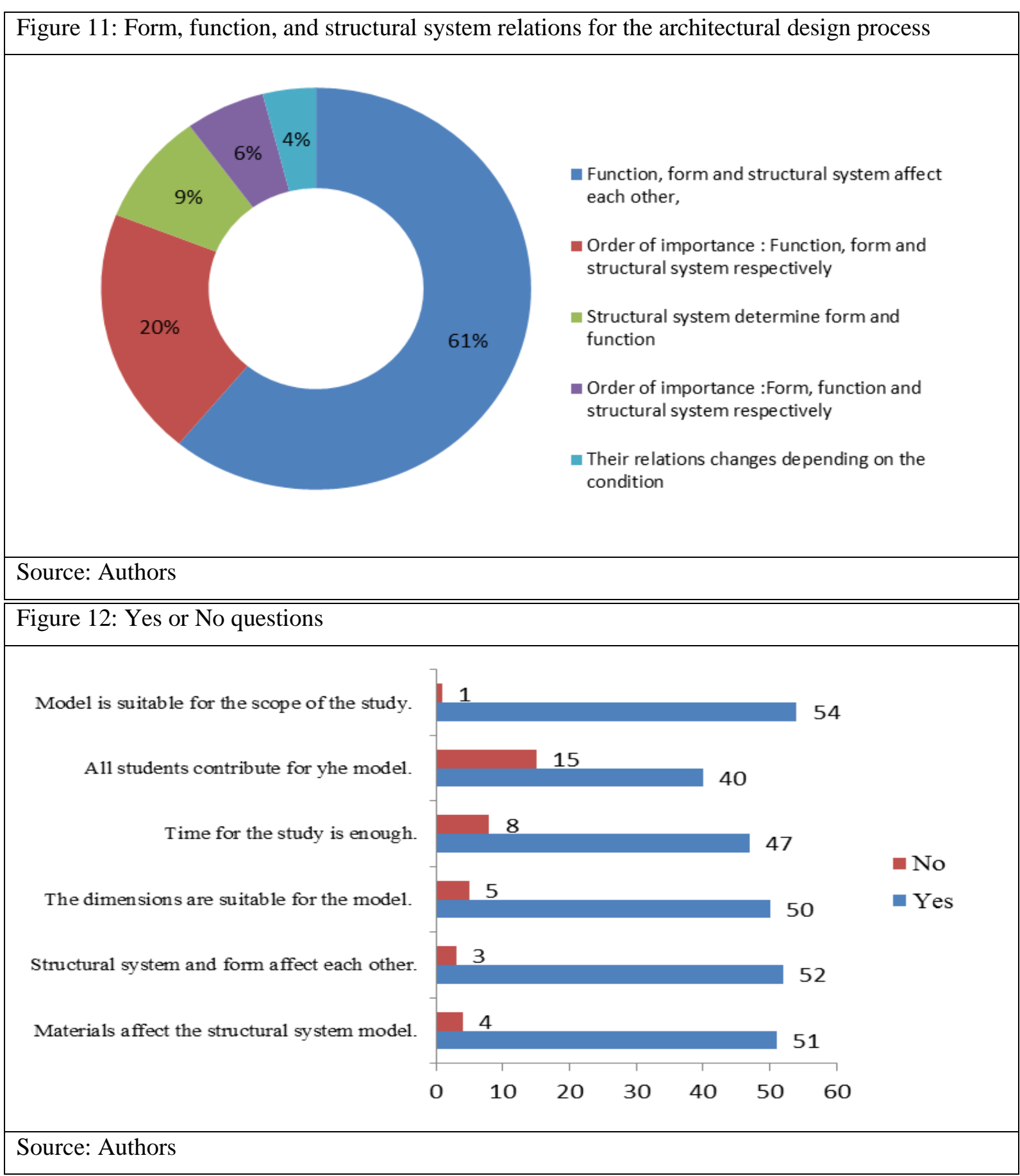

\section{Conclusion}

It was observed that a two-week practical study was successfully completed by the architecture students within the scope of the structural system course. The students have understood how to integrate their theoretical knowledge learned from structural system course into architectural design studio by the teaching method. It was also observed that architecture students are more interested to practical lessons than theoretical lessons in structural system course because they could learn more from constructing their structural system models. In architectural education, a good group work and solving a given problem in a short time are important for the students. In the future academic year, it is planned to continue short-term assignments, including multiple problems with the support of computer programs in the scope of structural system course. 


\section{References}

Aziz, A. A., Fahmi, M. M., \& Bane, L. T. (2010). Integration of Structural Knowledge in Design Studio Project: Assessment Study of Curriculum in Architecture Course in University Of Malaya. Retrieved from http://fbe.um.edu.my/images/fab/Files/JDBEVOL7/vol7-05.pdf

Erpi F. (1995, July). How is an architectural education, Mimarlı, 264(32), 17-18.

Hyett, P. (2000). Architecture Students must be properly equipped to practice. The Architectural Journal, 212.

İnceday1, D. (2010). Thoughts on Architectural Education from ACE and the EAAE Joint Meeting, Mimarist, 38(10), 93102.

İpekçi, C. A., \& Coşgun, N. (2011). Importance of Structural System Courses in Architectural Education. Structural Systems Symposium in Architecture. Proceedings book, 29-33. İstanbul.

Salvadori, H. (1975). Structure in Architecture. The Building of Building. New Jersey: Englewood Cliffs.

Thornberg, J. M. (2005). Architectural Design Education in Europe: Mind, Land and Society in a Global World. Ideas and Reflections on Architectural and Urban Design Education: EAAE Transactions on Architectural Education no.28. ed. Constantin Spiridonidis. Thessaloniki, Greece: Art of text S.A.

Vassigh, S. (2005). Structure learning center home. from www.learningstructures.org/home.asp. 